\title{
Sosialisasi Platform Teknologi Informasi Sekolah Menengah Kejuruan Pusat Keunggulan di SMK Negeri 10 Bengkulu Utara
}

\author{
Yulia Darnita ${ }^{1}$, Sastya H. Wibowo ${ }^{2}$, Rozali Toyib ${ }^{\star}$, Muntahanah ${ }^{4}$, Harry \\ Witriyono 5 \\ 1,2,3,4,5Universitas Muhammadiyah Bengkulu, Kota Bengkulu, Indonesia \\ *Corresponding Author: rozalitoyib@umb.ac.id
}

\begin{abstract}
Info Artikel Diterima: 21/02/2022 Direvisi: 24/02/2022 Disetujui: 25/02/2022
Abstract. The problem faced by schools in managing grant funds or school Operational Assistance is that there is often a confusion of information related to fund management, from planning, budgeting and reporting processes, the school is often confused when facing challenges due to misinformation, there is no source of validated questions and answers and integrated schools can be trusted to answer school confusion regarding the management of BOS funds, the existing question and answer channels (Whatshap, telegram) are still not integrated, have not been verified and tracked, the process of finding answers that are not well communicated adds to the administrative burden of educators, Not yet available application to help teachers and students in the teaching and learning process. Service activities in the form of socialization, practice, question and answer and Focus Group Discussion related to the use of digital platforms aimed at reducing complexity, increasing efficiency, adding inspiration, and customized approaches related to the School Resource Platform, the Merdeka Teaching Platform and the Teacher: Learning Platform. This community service process can be expected so that participants as the Assistance Team from Higher Education are able to: 1) Explore the Merdeka Mengajar Platform and its various products from their Android-based devices / devices (including web-based information systems via computers, desktops or laptops) 2) Explain the functions and the benefits of the Teaching Device Product on the Merdeka Mengajar Platform 3) Explaining the functions and benefits of the Student Assessment Product on the Merdeka Mengajar Platform 4) To teachers as the main users of the Merdeka Mengajar Platform (and its various products) as well as other key users such as school principals and stakeholders other related activities and need ongoing activities because most participants still need other training to help the learning process lead to a digital system, online-based and independent learning.
\end{abstract}

Keywords: Grants, School Operational Assistance (BOS), School resources, Independent learning platforms

\begin{abstract}
Abstrak. Permasalahan yang dihadapi pihak sekolah dalam pengelolahan dana hibah atau Bantua Operasional sekolah adalah sering terjadi kesimpangsiuran informasi terkait pengelolahan dana, mulai perencanaan, penganggaran belanja dan proses pelaporan pihak sekolah kerap sekali bingung ketika menghadapi tantangan karena adanya miss informasi, belum ada sumber tanya jawab tervalidasi dan terintegrasi dapat dipercaya sekolah untuk menjawab kebingungan sekolah terkait pengelolaan dana BOS, saluran tanya jawab yang ada (Whatshap, telegram ) masih belum bersifat terpaduh, belum terverifikasi dan terlacak, proses pencarian jawaban yang tidak terdekomuntasi dengan baik menambah beban administrasi para tenaga pendidik, Belum ada aplikasi untuk membantu guru dan siswa dalam proses belajar mengajar. Kegiatan pengabdian berupa sosialisasi, praktek, tanya jawab dan Fokus Group Discussion berhubungan dengan Penggunaan platform digital bertujuan mengurangi kompleksitas, meningkatkan efisiensi, menambah inspirasi, dan pendekatan yang customized berhubungan dengan Platform Sumber Daya Sekolah, Platform Merdeka Mengajar dan Platform Guru: Pembelajaran. Proses pengabdian masyarakat ini dapat diharapkan agar peserta sebagai Tim Pendamping dari Perguruan Tinggi mampu: 1) Mengeksplorasi Platform Merdeka Mengajar dan ragam produknya dari gawai/perangkat berbasis Android yang dimilikinya (termasuk sistem informasi berbasis web melalui komputer, desktop atau laptop) 2) Menjelaskan fungsi dan manfaat dari Produk Perangkat Ajar pada Platform Merdeka Mengajar 3) Menjelaskan fungsi dan manfaat dari Produk Asesmen Murid pada Platform Merdeka Mengajar 4) Kepada para Guru sebagai pengguna utama Platform Merdeka Mengajar (dan ragam produknya) maupun pengguna utama lainnya seperti Kepala Sekolah dan pemangku kepentingan lainnya yang terkait dan Perlu kegiatan berkelanjutan karena sebagian besar peserta masih butuh pelatihan yang lain membantu proses pembelajar mengarah ke sistem digital, berbasis daring dan merdeka belajar.
\end{abstract}

Kata Kunci: Hibah, Bantuan Operasional Sekolah (BOS), Sumber daya sekolah, Platform merdeka belajar.

How to Cite: Darnita, Y., Wibowo, S. H., Toyib, R., Muntahanah, M., \& Witriyono, H. (2022). Sosialisasi Platform Teknologi Informasi Sekolah Menengah Kejuruan Pusat Keunggulan di SMK Negeri 10 Bengkulu Utara. Prima Abdika: Jurnal Pengabdian Masyarakat, 2(1), 96-106. https://doi.org/10.37478/abdika.v2i1.1710 


\section{Pendahuluan}

Pemanfaatan platform teknologi untuk pembelajaran dan manajemen sekolah, bertujuan untuk mendukung implementasi kebijakan pendidikan yang akan diterapkan bagi SMK pelaksanan SMK Pusat Keunggulan baik untuk guru atau bagi sember daya sekolah digunakan untuk olrh guru untuk pembelajaran membantu kegiatan pengelolahan profil guru serta mendukung kegiatan pengembangan kompetensi guru di SMk yang dilakukan melalui media digital dan membantu kepala sekolah, bendahara dan pengawas sekolah dalam mengelolah sumber daya SMK dengan lebih tepat, mudah dan efisien. Peningkatan sumber daya sekolah baik itu untuk kepala sekolah, pengawas sekolah dan guru melalui pelatihan dan pendampingan intensif untuk mewujudkan manajemen dan pembelajaran berbasis dunia kerja serta penyelenggaraan pembelajaran yang berorientasi pada penguatan kompetensi sesuai dengan kebtuhan dunia kerja dan pengembangan karakter yang sesui nilai-nilai Pancasila serta banyaknya bantuan hibah untuk peningkatan sarana prasarna yang berfokus pada alat dan kelengkapan sarana belajar praktik siswa berstandar dunia kerja, kalaborasi dan koordinasi intens antara pemerintah untuk menciptkan dukungan penyelenggaraan SMK pusat keunggulaan yang berkesinambungan dan dilibatkan Perguruan Tinggi dalam mendampingi kegiatan ini sebagai perpanjang tangan dari dirjen Vokasi Kemenristek-brin yang berpungsi sebagai mentor, supervise dan konsultan dalam mensukseskan program SMK PK.

Ada 3 paltform teknologi SMK Pusat Keunggulan yaitu platform merdeka mengajar, platform sumber daya sekolah, dashboard (platform rapor Pendidikan yang masing-masing aplikasi membantu guru, kepala sekolah, bendahara, pengawas sekolah dalam keterbukaan informasi penggunaan anggaran baik itu hibah maupun penggunaan dana bantuan Operasional Sekolah (BOS) sehingga tidak terjadi lagi Mal administrasi karena ketidaktauan pihak sekolah dalam pengelolahan dana tersebut untuk ituah perlu dilakukan sosialisasi penggunaan platform teknologi ini kepada pihak sekolah oleh Perguruan tinggi pendamping yang diamant untuk mensosialisasikan kepada pihak sekolah seperti penggunaan aplikasi pengembangan sumber daya manusia yang berfokus untuk memfasilitasi proses pengelolaan sumber daya sekolah agar lebih efisien dan akutabel dan berorientasi pada peningkatan hasil pembelajaran siswa, saat ini terdiri adari 3 aplikasi yang saling mengisi satu dengan yang lainnya:

1. ARKAS untuk perencanaan, penganggaran, penatusahaan dan pelaporan

2. SIPLAH untuk membantu sekolah melakukan pengadaan

3. TanyaBOS untuk membantu sekolah beriteraksi dan mendapatkan informasi terpercaya mengenai isu-isu berkaitan dengan pengelolaan dana BOS.

Permasalahan yang dihadapi oleh pihak sekolah dan pengelolahan dana hibah atau Bantua Operasional sekolah adalah:1) sering terjadi kesimpangsiuran informasi terkait kebijakan pengelolahan dana baik mulai perencanaan, penganggaran berbelanja dan proses pelaporan pihak seekolah kerap seklai bingung Ketika menghadapi tatantangan tersebut karena sering terjadi misinformasi 2) belum ada sumber tanya jawab tervalidasi dan terintegrasi yang dapat dipercaya sekolah untuk menjawab kebingungan sekolah terkait pengelolaan dana BOS 3) Saluran tanya jawab yang ada 
(Whatshap, telegram ) masih belum bersifat terpaduh, belum terverifikasi dan terlacak 4) Proses pencarian jawaban yang tidak terdekomuntasi dengan baik menambah beban administrasi para tenaga pendidik 5) Belum ada aplikasi untuk membantu guru dan siswa dalam proses belajar mengajar.

Penelitian sebelumnya Sosialisasi dalam Kamus Besar Bahasa Indonesia (KBBI) setidaknya memiliki 3 (tiga) arti sebagai berikut: Pertama, suatu usaha untuk mengubah milik seseorang/perseorangan menjadi milik umum atau milik negara (Herdiana, 2018), Komunikasi sebagai tindakan satu arah (directional) merupakan komunikasi yang mengisyaratkan penyampaian pesan searah dari seseorang (atau suatu lembaga) kepada seseorang (sekelompok orang) lainnya, baik secara langsung (tatap muka) ataupun melalui media, seperti surat (selebaran), surat kabar, majalah, radio, atau televisi (Putri, 2016), Sosialisasi merupakan suatu proses yang berlangsung sepanjang hidup manusia, dalam kaitan inilah para ahli berbicara mengenai bentuk-bentuk proses sosialisasi seperti sosialisasi setelah masa kanakkanak (socialisation after childhood), pendidikan sepanjang hidup (life long education) atau pendidikan yang berkesinambungan (continuing education)(Suryani, 2005).

Teknologi informasi merupakan ilmu yang mengalami perkembangan dari masa ke masa yang kita nikmati saat ini didukung oleh infrastruktur teknologi informasi, yang terdiri dari perangkat keras, perangkat lunak, dan layanan teknologi informasi dan layanan-layanan teknologi informasi dimanfaatkan dalam kehidupan manusia di berbagai aspek(Arifin, 2017). Child Tracker adalah sebuah perangkat lunak yang berjalan pada perangkat mobile sehingga mudah untuk diakses dan di bawa kemana saja, Child Tracker menggunakan teknologi Assisted Global Positioning System (AGPS),penentu posisi pada GPS dengan bantuan server pembantu dari BTS sellule(Juansyah, 2015). Belajar daring (online) dapat menggunakan teknologi digital seperti google classroom, rumah belajar, zoom, video converence, telepon atau live chat dan lainnya. Beberapa sekolah yang belum dapat menyelenggarakan KBM daring dapat mengembangkan kreativitas guru untuk memanfaatkan media belajar alternatif selama peserta didik belajar di rumah(Eka Yuda Wibawa, 2021). Teknologi Informasi dan Komunikasi (TIK) sebagai bagian dari Ilmu Pengetahuan dan Teknologi (IPTEK) secara umum adalah semua teknologi yang berhubungan dengan pengambilan, pengumpulan (akuisisi), pengolahan, penyimpanan, penyebaran dan penyajian informasi (Kementerian Negara Riset dan Teknologi(Hasrah, 2019). Teknologi informasi memilki kekuatan untuk mengembangkan industry dan mentranformasikan bagaimana bisnis dijalankan oleh perusahan sebagai kekuatan dalam melakukan strategi bisnis, proses, dan praktek manajemen(Aziz, 2015).

Sekolah Menengah Kejuruan adalah salah satu jenjang pendidikan menengah dengan kekhususan mempersiapkan lulusannya untuk siap bekerja, pendidikan kejuruan adalah bagian dari sistem pendidikan yang mempersiapkan seseorang agar lebih mampu bekerja pada suatu kelompok pekerjaan atau satu bidang pekerjaan (Ariyanto et al., 2018). Pendidikan Teknologi Kejuruan memiliki beberapa istilah di berbagai negara. Namun berdasarkan hasil kongres kedua 26-29 April 1999 dengan tema Technical and Vocational Education and Training: A Vision for the Twenty-first Century.Menghasilkan terminologi Technical and Vocational Education and 
Training (TVET) termasuk pendidikan vokasi meliputi pendidikan dan pelatihan formal, nonformal, dan informal(Jama, 2018). Pendidikan kejuruan memiliki karakteristik yang berbeda dengan pendidikan umum, baik ditinjau dari kriteria pendidikan, substansi pelajaran, maupun lulusannya. Kriteria yang melekat pada sistem pendidikan kejuruan menurut Finch dan Crunkilton (1984: 12-13) antara lain (1) orientasi pendidikan dan pelatihan; (2) justifikasi untuk eksistensi dan legitimasi; (3) fokus pada isi kurikulum; (4) kriteria keberhasilan pembelajaran; (5) kepekaan terhadap perkembangan masyarakat; dan (6) hubungan kerjasama dengan masyarakat. Nolker (1983), menyatakan bahwa dalam memilih substansi pelajaran, pendidikan kejuruan harus selalu mengikuti perkembangan IPTEK, kebutuhan masyarakat, kebutuhan individu, dan lapangan kerja(Kejuruan, 2015). Pemerintah terus melakukan pembenahan melalui berbagai upaya, salah satunya pendidikan kejuruan sebagaimana ditegaskan dalam penjelasan pasal 15 UU SISDIKNAS No. 20 Tahun 2003 (Departemen Pendidikan Nasional, 2003), SMK sebagai bentuk satuan pendidikan kejuruan merupakan pendidikan menengah yang mempersiapkan peserta didik terutama untuk bekerja dalam bidang tertentu(Sekolah \& Kejuruan, 2013).

SMK Pusat Keunggulan (SMK PK) merupakan salah satu program prioritas dari Direktorat Jenderal Pendidikan Vokasi (Ditjen Pendidikan Vokasi) Kemendikbud pada tahun 2021, program ini sebagai upaya pengembangan SMK dengan program keahlian tertentu, meningkatkan kualitas hasil belajar siswa yang sesuai dengan standar dunia usaha dan dunia industri (DUDI) atau dunia kerja(Fahmayani, n.d.). Sekolah unggulan dapat diartikan sebagai sekolah bermutu, dan secara tersirat ada harapan yang dimiliki oleh murid setelah keluar dari sekolah unggulan, yaitu sejauh mana keluaran (output) sekolah itu memiliki kemampuan intelektual, moral dan keterampilan yang dapat berguna bagi masyarakat (Hermiyanty \& Wandira Ayu Bertin, 2017). Perubahan sistem pendidikan yang terjadi di Indonesia dari waktu ke waktu bertujuan untuk memasuki era globalisasi yang diwarnai oleh persaingan tenaga kerja yang semakin ketat, persaingan kualitas SDM mencakup semua sektor kehidupan, seperti sektor pendidikan maupun sektor industri yang mempunyai peran yang sama yaitu sama-sama menghasilkan suatu produk/jasa (Daoed et al., 2020).

Tujuan dari sosialisi penggunaan platform teknologi ini adalah upaya untuk membatu pihak sekolah baik itu kepala sekolah (sumber daya sekolah) dan Guru dalam pengelolahan dana Hibah, dana BoS dan pengmbengan aplikasi Merdeka Belajar sehingga kegiatan disekoah bisa berjalan lancer dan tidak ada temuan dalam pengolalahan anggaran baik itu hibah maupun dana Bos.

\section{Metode Pelaksanaan}

Pelaksanaan pengabdian program pengabdian masyarakat ini dilakukan dengan melakukan solusi yang dirancang pada solusi permasalahan dengan menggunakan kompetensi dari para anggota di bidangnya dan dibantu tim pelaksana pengabdian ini. Sasaran dari kegiatan ini adalah Kepala Sekolah, pengawas, Manajemen sekolah dan Guru di Sekolah Menengah Kejuruan SMK Negeri 10 Bengkulu Utara,.

Mekanisme pelaksanaan kegiatan PKM meliputi tahapan berikut:

a. Perekrutan mahasiswa untuk Membantu Proses PKM 
b. Konsultasi dengan Kepala Sekolah diadakan PKM

c. Pembekalan (coaching)

d. Penyiapan alat dan bahan untuk kegiatan PKM PKM:

Materi persiapan dan pembekalan kepada mahasiswa yang terlibat dalam

1. Sesi pembekalan/coaching :

a. Pembagian Tugas Kepada mahasiswa yang terlibat dalam PKM

b. Panduan dan pelaksanaan program kerja PKM oleh ketua

2. Sesi pembekalan/simulasi:

a. Persiapan materi ajar yang akan diberikan serta teknik pembagian kelas dan alokasi waktu

b. Mekanisme pelaksanaan dalam bentuk metode yang akan digunakan dalam pengajaran nanti.

3. Pelaksanaan tahapan kegiatan PKM tahun 2021 :

a. Melakukan Tutorial/workshop Platform Merdeka Belajar

b. Melakukan Tutorial menjalankan Platform Merdeka Belajar

c. Melakukan Klinik pengerjaan tugas di lembar kerja komputer

d. Monitoring dan evaluasi kegiatan

Detail dari metode pelaksanaan dapat diperlihatkan pada Tabel 1 . Pelaksanaan ini dilakukan dengan dikelola oleh ketua anggota dan tim pelaksana pengabdian ini yang memiliki keahlian sesuai dengan bidang kegiatan yang akan dilakukan.

Tabel 1. Metode pelaksanaan program kemitraan masyarakat

\begin{tabular}{|c|c|c|c|c|c|}
\hline No & $\begin{array}{l}\text { Metode } \\
\text { Pelaksanaan }\end{array}$ & Uraian Kegiatan & Waktu & Tempat & $\begin{array}{l}\text { Penanggung } \\
\text { Jawab }\end{array}$ \\
\hline 1 & $\begin{array}{l}\text { Dasar Hukum } \\
\text { Platform } \\
\text { Teknologi SMK } \\
\text { Pusat } \\
\text { Keunggulan } \\
\text { Kepmendikbudri } \\
\text { stek } \\
\text { No.165/M/2021 } \\
\text { tentang Program } \\
\text { SMK Pusat } \\
\text { Keunggulan }\end{array}$ & $\begin{array}{l}\text { Penguatan Kepala } \\
\text { Sekolah, Pengawas } \\
\text { Sekolah, dan Guru } \\
\text { melalui program } \\
\text { pelatihan dan } \\
\text { pendampingan } \\
\text { intensif untuk } \\
\text { mewujudkan } \\
\text { manajemen dan } \\
\text { pembelajaran } \\
\text { berbasis dunia kerja }\end{array}$ & $\begin{array}{l}\text { Minggu } \\
\text { Pertama } \\
\text { Nopember }\end{array}$ & $\begin{array}{l}\text { SMK Negeri } 10 \\
\text { Bengkulu Utara }\end{array}$ & $\begin{array}{l}\text { Yulia Darnita } \\
\text { (Ketua) } \\
\text { Harry Witriyono } \\
\text { (Tim Pelaksana) }\end{array}$ \\
\hline 2 & $\begin{array}{l}\text { Platform Guru: } \\
\text { Profil dan } \\
\text { Pengembangan } \\
\text { Kompetensi }\end{array}$ & $\begin{array}{l}\text { Alat bantu Guru } \\
\text { untuk meningkatkan } \\
\text { kompetensi melalui } \\
\text { pembelajaran } \\
\text { berbasis } \\
\text { microlearning dan } \\
\text { habituasi }\end{array}$ & $\begin{array}{l}\text { Minggu } \\
\text { Pertama } \\
\text { Nopember }\end{array}$ & $\begin{array}{l}\text { SMK Negeri } 10 \\
\text { Bengkulu Utara }\end{array}$ & $\begin{array}{l}\text { Dr. Sastya } \\
\text { H.Wibowo, M.Kom } \\
\text { (Anggota) } \\
\text { (Tim Pelaksana) }\end{array}$ \\
\hline 3 & $\begin{array}{l}\text { Platform Sumber } \\
\text { Daya Sekolah }\end{array}$ & $\begin{array}{l}\text { Meningkatkan } \\
\text { fleksibilitas, } \\
\text { transparansi dan } \\
\text { akuntabilitas dalam } \\
\text { manajemen sumber } \\
\text { daya sekola }\end{array}$ & $\begin{array}{l}\text { Minggu } \\
\text { Pertama } \\
\text { Nopember }\end{array}$ & $\begin{array}{l}\text { SMK Negeri } 10 \\
\text { Bengkulu Utara }\end{array}$ & $\begin{array}{l}\text { Rozali Toyib, } \\
\text { M.Kom } \\
\text { (Anggota) } \\
\text { (Tim Pelaksana) }\end{array}$ \\
\hline 4 & $\begin{array}{l}\text { Platform Guru: } \\
\text { Pembelajaran }\end{array}$ & $\begin{array}{l}\text { Alat bantu Guru } \\
\text { untuk menjalankan } \\
\text { pembelajaran } \\
\text { kompetensi holistik } \\
\text { dan pembelajaran } \\
\text { terdiferensiasi }\end{array}$ & $\begin{array}{l}\text { Minggu } \\
\text { Pertama } \\
\text { Nopember }\end{array}$ & $\begin{array}{l}\text { SMK Negeri } 10 \\
\text { Bengkulu Utara }\end{array}$ & $\begin{array}{l}\text { Muntahanah, } \\
\text { M.Kom } \\
\text { (Anggota) } \\
\text { (Tim Pelaksana) }\end{array}$ \\
\hline
\end{tabular}


Tabel 2. Bidang Keahlian Tim Pengabdian

\begin{tabular}{|c|c|c|c|c|c|}
\hline No & Nama & Jabatan & Bidang Keahlian & Instansi Asal & $\begin{array}{c}\text { Alokasi } \\
\text { Waktu } \\
(\mathbf{h} / \mathbf{w})\end{array}$ \\
\hline 1 & Yulia Darnita, M.Kom & Ketua & Web Disain & $\begin{array}{l}\text { Program Studi Teknik } \\
\text { Informatika, FT UMB }\end{array}$ & 10 \\
\hline 2 & $\begin{array}{l}\text { Dr. Sastya H. Wibowo, } \\
\text { M.Kom }\end{array}$ & Anggota & $\begin{array}{l}\text { Manajemen } \\
\text { Sistem }\end{array}$ & $\begin{array}{l}\text { Program Studi Teknik } \\
\text { Informatika, FT UMB }\end{array}$ & 10 \\
\hline 3 & Harry Witriyono, M.Kom & & & & \\
\hline 4 & Rozali Toyib, M.Kom & Anggota & $\begin{array}{l}\text { Teknologi } \\
\text { Informasi }\end{array}$ & $\begin{array}{l}\text { Program Studi Teknik } \\
\text { Informatika, FT UMB }\end{array}$ & 10 \\
\hline 5 & Muntahanah, M.Kom & Anggota & $\begin{array}{l}\text { Manajemen } \\
\text { Database }\end{array}$ & $\begin{array}{l}\text { Program Studi Teknik } \\
\text { Informatika, FT UMB }\end{array}$ & 10 \\
\hline
\end{tabular}

\section{Hasil dan Pembahasan}

Acara dibuka oleh MC dan selanjutnya kata sambutan dari Kepala Sekolah Sekolah Menengah Kejuruan Negeri 10 Bengkulu Utara, ucapan selamat datang kepada peserta dan pemateri yang bersedia hadir pada acara Pengabdian Kepada Masyarakat ini serta sedikit wejangan kepada peserta untuk mengikuti rangkaian acara dan berharap ada manfaat dari kegiatan ini dan membuka acara secara resmi dan dilanjutkan dengan sepatah dua patah dari ketua tim pelaksanaan Pengabdian kepada Masyarakat.
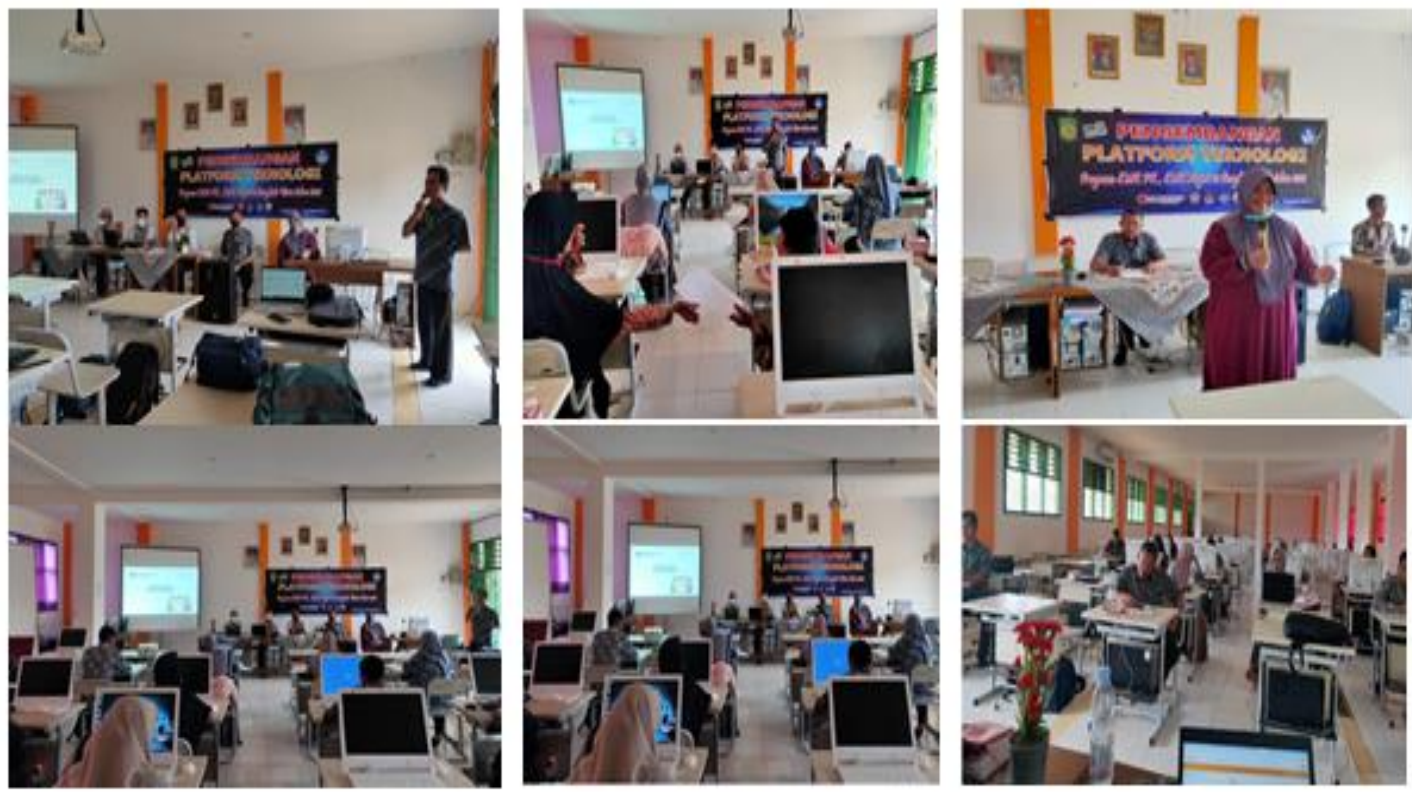

Gambar 1. Pembukaan Kegiatan Sosialisasi Platform Teknologi

Kegiatan pengabdian berupa sosialisasi, praktek, tanya jawab dan Fokus Group Discussion (FGD) berhubungan dengan Penggunaan berbagai platform digital bertujuan mengurangi kompleksitas, meningkatkan efisiensi, menambah inspirasi, dan pendekatan yang customized berhubungan dengan Platform Sumber Daya Sekolah, Platform Merdeka Mengajar dan Platform Guru: Pembelajaran.

Platform Sumber Daya Sekolah digunakan Untuk memfasilitasi proses pengelolaan sumber daya sekolah agar lebih efisien, efektif, dan akuntabel dan berorientasi pada peningkatan hasil pembelajaran siswa, Saat ini SDS sendiri terdiri dari 3 aplikasi yang saling mengisi satu dengan lainnya:1) 
ARKAS untuk perencanaan, penganggaran, penatausahaan, dan pelaporan 2) SIPLah untuk membantu sekolah melakukan pengadaan 3) TanyaBOS untuk membantu sekolah berinteraksi dan mendapat informasi terpercaya mengenai isu-isu berkaitan dengan pengelolaan dana BOS. Para pengguna SIPLah adalah Kepala Sekolah, bendahara, atau tim BOS Sekolah yang biasanya mengalami tantangan-tantangan dalam mengelola dana BOS di sekolahnya karena banyak Tantangan tidak hanya di temukan ketika berbelanja SIPLah, tapi juga ada sejak tahap perencanaan hingga pelaporan BOS dan Sekolah kerap kali merasa bingung ketika menghadapi tantangan tersebut karena sering terjadi misinformasi di lapangan. Tanya Bos adalah Forum tanya jawab dan sharing aspirasi baik bagi sekolah terkait pengelolaan dana BOS yang dilatar belakangi oleh Sering terjadinya kesimpangsiuran informasi terkait kebijakan pengelolaan dana BOS di sekolah meskipun sudah diatur dalam Juknis BOS, Belum adanya sumber jawaban tervalidasi dan terintegrasi yang dapat dipercaya sekolah untuk menjawab kebingungan terkait pengelolaan dana BOS, Saluran tanya jawab yang ada (Whatsapp, telegram) masih belum bersifat terpadu, belum terverifikasi dan terlacak dan Proses pencarian jawaban yang tidak terdokumentasikan dengan baik menambah beban administrasi para tenaga pendidik.

Tujuan dari TanyaBOS adalah Menyediakan forum tanya jawab dan sharing aspirasi baik, yang terverifikasi dan tervalidasi bagi sekolah seputar pengelolaan dana BOS, untuk menghilangkan keragu-raguan saat mengelola dana BOS dan Membuat proses tanya jawab dalam forum menjadi lebih efektif, efisien, terlacak dan terarah. Pertanyaan atau keluhan terkait tanyaBOS bisa melalui tanyabos@wartek.belajar.id dengan subjek email TanyaBOS-Keluhan/Pertanyaan/Saran-Nama-Asal Sekolah
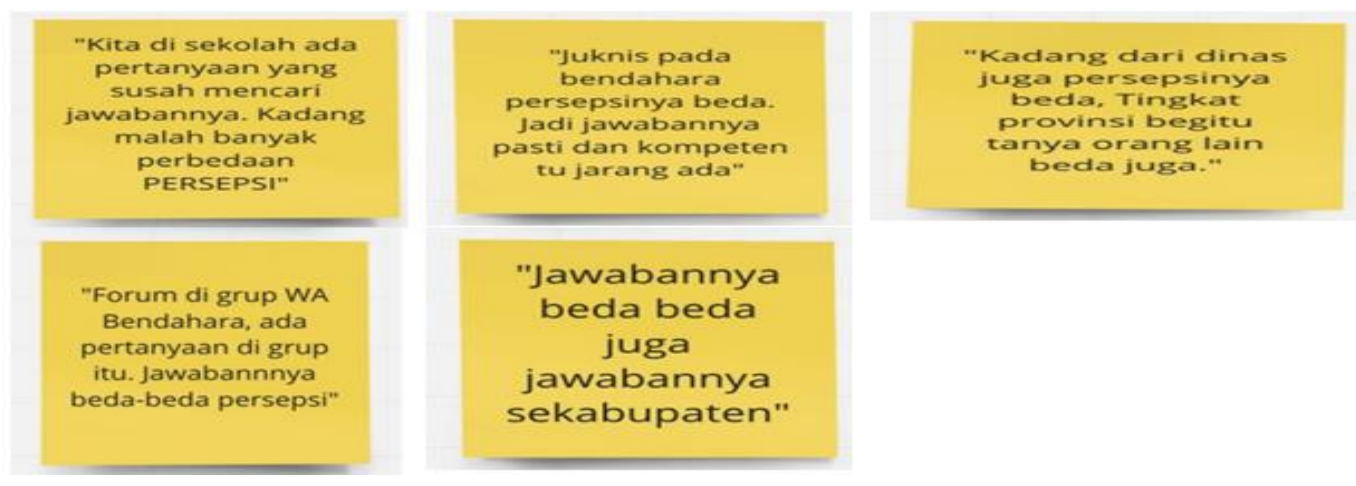

Gambar 2. Hal-hal yang menjadi pertanya bagi pihak sekolah dalam penggunaan dana BOS

Platform Merdeka Mengajar Salah satu platform teknologi yang disediakan untuk mendukung para guru agar dapat mengajar lebih baik, meningkatkan kompetensinya, dan berkembang secara karier. Platform ini akan terus berkembang ke depannya dengan fitur-fitur yang dapat membantu guru menjadi pendidik yang lebih baik kedepannya. Penggunaannya adalah Memperkenalkan dan mengimplementasikan Profil Pelajar Pancasila sebagai dasar pembelajaran dengan paradigma baru, Memudahkan guru untuk menemukan perangkat ajar berdasarkan pembelajaran dengan paradigma baru, Guru mendapatkan kejelasan tentang kompetensi dan perkembangan pembelajaran siswanya, Guru mendapatkan rekomendasi perangkat ajar 
berdasarkan hasil asesmen (penilaian) dan Guru dapat menerapkan teaching at the right level (TaRL).
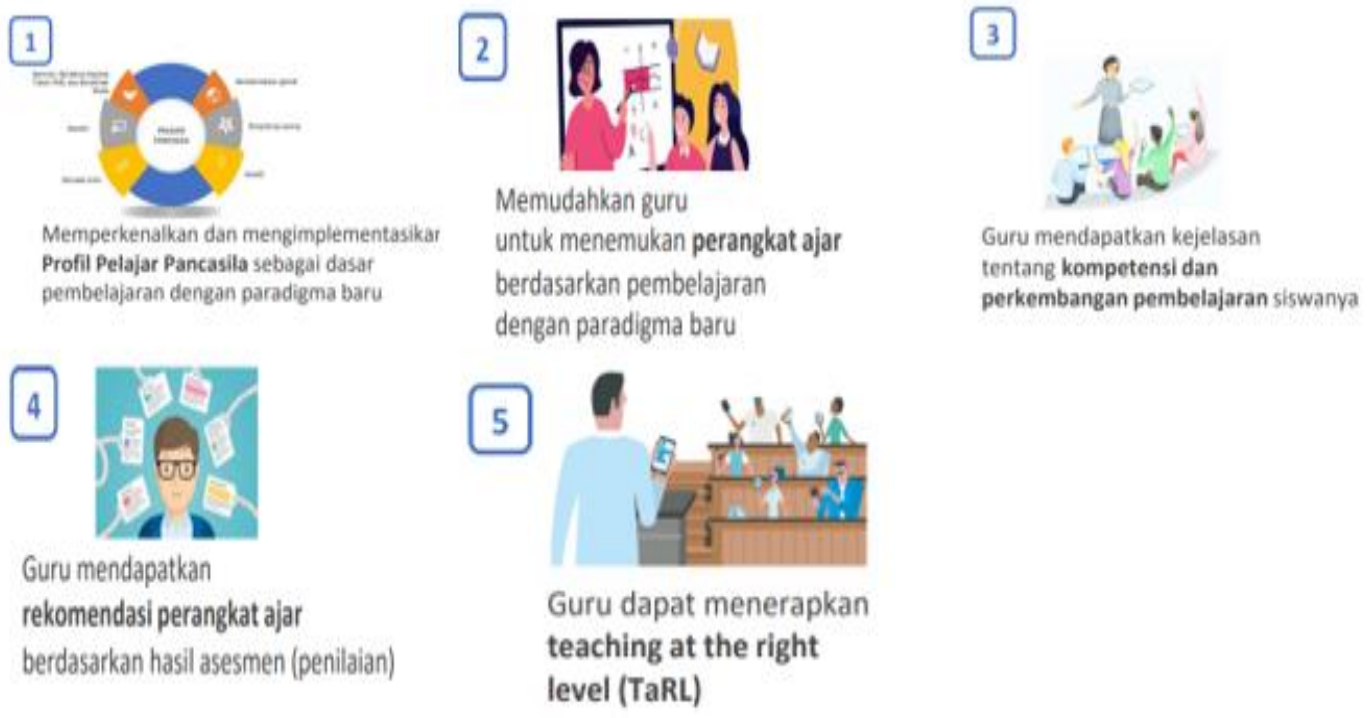

Gambar 3. Hilustrasi Penggunaan Merdeka Belajar

Produk Perangkat Ajar dalam Platform Merdeka Mengajar ini menyediakan perangkat ajar seperti diantaranya: Modul Ajar/RPP+ dan Buku Teks (Buku Guru dan Buku Murid) yang sudah sesuai dengan paradigma pembelajaran baru, Untuk itu, Produk Perangkat Ajar memiliki fungsi dan manfaat: 1) Mencari Perangkat Ajar 2) Mengunduh Buku Teks 3) Mengunduh Modul Ajar 4) Menandai dan menambahkan Modul Ajar ke Folder 5) Mengelola Folder.

Dengan fitur pencarian perangkat ajar, guru dapat mencari modul ajar, buku murid, atau buku guru berdasarkan mata pelajaran dan fase yang diinginkan. Selain itu, guru juga dapat menyaring modul ajar berdasarkan kelas, Gunakan tools/alat bantu yang disediakan oleh Produk Perangkat Ajar untuk membantu Anda dalam pencarian Perangkat Ajar yang diperlukan dan Temukan hasil pencarian Anda pada daftar di bagian Pilihan Perangkat Ajar dengan menggulirkan (scrolling) tampilan dan klik hasil pencarian Anda tersebut untuk mendapatkan Perangkat Ajarnya. Eksplorasi Fungsi dan Manfaat Produk Asesmen Murid dimana Produk Asesmen Murid dalam Platform Merdeka Mengajar bertujuan membantu Guru untuk mendapatkan peta kompetensi para murid di dalam kelasnya agar tercipta kegiatan belajarmengajar yang sesuai dengan tingkat kemampuan para murid. Saat ini Produk Asesmen Murid baru menyediakan jenis Asesmen Diagnostik dengan tampilan manfaat penilaian yang dikembangkan secara bertahap, Untuk itu, Produk Asesmen Murid saat ini memiliki fungsi dan manfaat: 1) Mencari Asesmen Diagnostik 2) Menggunakan Asesmen Diagnostik (mendistribusikan Asesmen Diagnostik kepada para murid) 3) Melakukan Penilaian untuk Jawaban Uraian.

Untuk memulai pengelolaan kelas dan murid yang dapat dilakukan di Platform Merdeka Mengajar, Guru perlu membuat kelas-kelas yang diajar pada tahun ajaran tersebut. Dengan membuat kelas ini, Guru dapat mengelola murid pada kelasnya, serta dapat melihat analisis penilaian dari 
asesmen yang sudah dikerjakan oleh murid. Guru dapat mengelola kelasnya dengan menambah data murid yang dapat diintegrasikan dengan hasil asesmen nantinya. Sehingga, pada saat murid selesai menyelesaikan soal, hasil analisis dari asesmen dapat dilihat berdasarkan individu murid. Penambahan murid dapat dilakukan sesuai dengan jumlah murid pada kelas yang sesungguhnya. Data murid juga dilengkapi dengan isian tanggal lahir dan NISN. Selain menambah data murid pada kelas, Guru juga dapat menghapus data murid pada kelas tersebut jika tidak sesuai. Jika pada kelas ada data murid yang tidak sesuai, Guru dapat menghapus data murid. Setelah membagikan asesmennya ke murid, Guru dapat melihat hasil asesmen yang sudah dikerjakan oleh murid. Pada laman ini, guru dapat melihat status pengerjaan asesmen sudah berapa murid, melihat uraian yang belum diperiksa, dan juga melihat analisis dari hasil pengerjaan asesmen oleh murid.
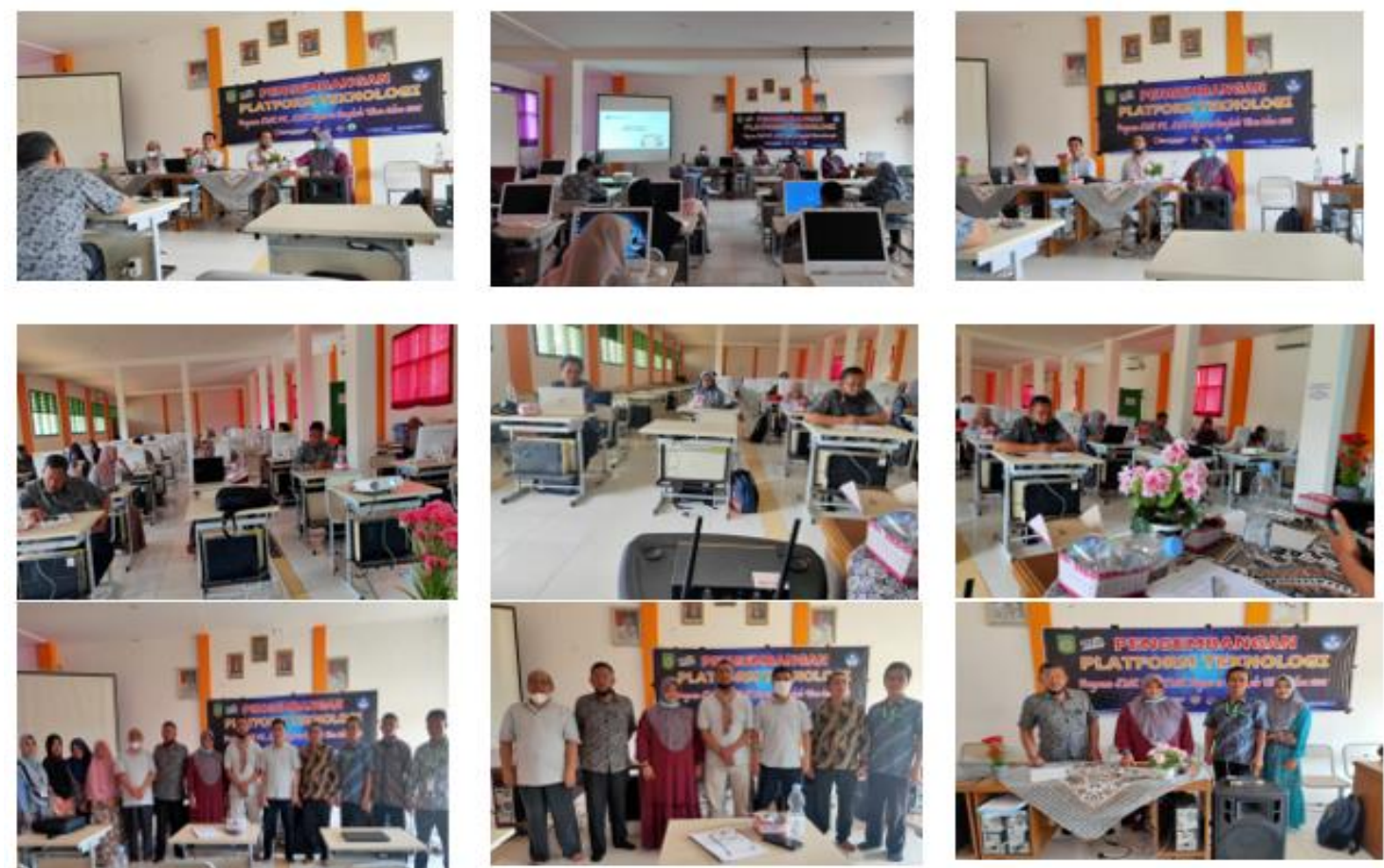

Gambar 4 . Suasana Kegiatan Pengabdian Kepada masyarakat berhubungan dengan Platform Teknologi Untuk SMK PK

\section{Pembahasaan}

Mitra berpartisifasi penuh dengan menyediakan waktu, tenaga, pikiran serta menyiapkan sarana prasarana, guru, staf, ruang kelas dan fasilitasnya, serta sarana prasarana di sekolah mitra yang terkait dengan kegiatan dalam rangkah suksesnya kegiatan Pengabdian Kepada Masyarakat ini dan antusias peserta untuk mengkuti dengan sungguh dimana hampir setiap hari pesertanya hadir dan berpartisipasi dengan mengajukan pertanyaanpertanyaan dan memintah pemateri untuk menjelaskan lebih lanjut dari materi yang ada.

\section{Langkah Evaluasi Pelaksanaan Program}

Evaluasi program pelaksanaan program dilakukan dengan maksud untuk mengetahui sampai dimana tingkat ketercapaian program yang telah dilakukan dan ingin mengetahui letak kekurangan dan penyebabnya. Dalam 
kegiatan PKM ini dilakukan evaluasi terhadap kegiatan PKM ini adalah dengan cara evaluasi jangka pendek dan evaluasi jangka penjang, diantaranya:

1. Evaluasi Jangka Pendek : 1) setelah menjelaskan maksud dan tujuan serta luaran yang diharapkan dari kerjasama kepada Mitra, kemudian akan diberikan kuis pre test dan post tes tentang bagaimana pengetahuan para guru tentang platform teknollogi 2) memastikan bahwa kepala sekolah, pengawas sekolah, manajemen sekolah dan para guru (mitra) memiliki kesungguhan dan memahami pentingnya penggunaan platform teknologi untuk peningkataan sumber daya sekolah dalam peningkatan mutu pembelajaran dan pembenahan prasaran disekolah.

2. Evaluasi dalam jangka panjang melakukan pemantauan dalam kurun waktu 6 bulan

Tabel 3. Evaluasi / Indikator Kerja Kegiatan PKM

\begin{tabular}{clcc}
\hline No & \multicolumn{1}{c}{ Kegiatan } & $\begin{array}{c}\text { Waktu Pelaksanaan } \\
\text { (hari/bulan ke-) }\end{array}$ & $\begin{array}{c}\text { Indikator } \\
\text { Kerja }\end{array}$ \\
\hline 1 & Administrasi kegiatan & $\begin{array}{c}\text { 2-3 hari } \\
\text { 3 hari }\end{array}$ & $\begin{array}{c}50 \% \\
80 \%\end{array}$ \\
2 & $\begin{array}{l}\text { Kegiatan persiapan alat dan } \\
\text { bahan (penyusunan tupoksi }\end{array}$ & $95 \%$ \\
$\quad \begin{array}{l}\text { tim, pembuatan modul ) } \\
3\end{array}$ & Pelaksanaan & $100 \%$ \\
pelatihan/workshop & hari & $75 \%$ \\
4 & $\begin{array}{l}\text { Evaluasi kegiatan } \\
\text { Laporan kegiatan }\end{array}$ & $5-6$ hari & $100 \%$ \\
\hline
\end{tabular}

\section{Simpulan dan Tindak Lanjut}

Setelah mengikuti pelatihan ini dapat disimpulkan: 1. Peserta bisa menggunakan aplikasi Mengeksplorasi Platform Merdeka Mengajar dan ragam produknya dari gawai / perangkat berbasis Android yang dimilikinya (termasuk sistem informasi berbasis web melalui komputer, desktop atau laptop) 2. Mampu manfaat dari Produk Perangkat Ajar pada Platform Merdeka Mengajar, 3. Perlu kegiatan berkelanjutan, karena sebagian besar peserta masih butuh pelatihan-pelatihan yang lain yang membantu proses pembelajar yang mengarah ke sistem digital, berbasis daring dan merdeka belajar.

\section{Daftar Pustaka}

Arifin, Z. (2017). Pengertian dan Ruang Lingkup Infrastruktur Teknologi Informasi. 1-36.

Ariyanto, F., Muslihudin, M., Beasiswa, P., Smk, P., Palembang, N., Beasiswa, P., Smk, P., Palembang, N., Rasyid Ridho, M., Hairani, H., Abd Latif, K., Hammad, R., Mainingsih, R. D., Hamka, M., Sari, N. N. K., Widiatry, W., Chitayae, N., Noviyanti, T., Fadlan, M., ... sembiring, muhammad ardiansyah. (2018). Spk Topsis. Anterior Jurnal, 18(1), 35-45. http://dx.doi.org/10.31227/osf.io/t8r5q\%0Ahttps:// juurnal.teknokrat.ac .id/index.php/teknokompak/article/view/905

Aziz, A. (2015). Pemanfaatan Teknologi Informasi dalam Pengembangan Bisnis Pos. Buletin Pos Dan Telekomunikasi, 10(1), 35. https://doi.org/10.17933/bpostel.2012.100104 
Daoed, T. S., Nasution, M. A., \& Firah, A. (2020). Berbasis Kurikulum Smks Tik. Jurnal Pengabdian Kepada Masyarakat, 1(Januari), 56-64.

Eka Yuda Wibawa, A. (2021). Implementasi Platform Digital Sebagai Media Pembelajaran Daring Di Mi Muhammadiyah Pk Kartasura Pada Masa Pandemi Covid-19. Berajah Journal, 1(2), 76-84. https://doi.org/10.47353/bj.v1i2.15

Fahmayani, E. N. (n.d.). PELAKSANAAN LINK AND MATCH 8 + I DI SMK PUSAT KEUNGGULAN SMKN 1 DLINGO.

Hasrah, H. (2019). Pemanfaatan Teknologi Komunikasi Dan Informasi Dalam Pembelajaran PKN. Phinisi Integration Review, 2(2), 238. https://doi.org/10.26858/pir.v2i2.10002

Herdiana, D. (2018). Sosialisasi Kebijakan Publik: Pengertian dan Konsep Dasar. Jurnal Ilmiah Wawasan Insan Akademik, I(3), 13-26. http:/ /www.stiacimahi.ac.id/?page_id=1181\%0Ahttps:/ / www.researchga te.net/publication/337485273_Sosialisasi_Kebijakan_Publik_Pengertian_ dan_Konsep_Dasar

Hermiyanty \& Wandira Ayu Bertin, D. S. (2017). Manajemen Pengembangan Mutu Sekolah Menengah Kejuruan Swasta Dalam Peningkatan Keunggulan Bersaing. Journal of Chemical Information and Modeling, 8(9), $1-58$.

Jama, J. (2018). Philosophy Tvet Di Era Derupsi. Jurnal Filsafat Indonesia, 1(3), 104-111.

Juansyah, A. (2015). Pembangunan Aplikasi Child Tracker Berbasis Assisted Global Positioning System ( A-GPS ) Dengan Platform Android. Jurnal Ilmiah Komputer Dan Informatika (KOMPUTA), 1(1), 1-8.

Kejuruan, D. P. sekolah M. (2015). Peran Pendidikan Kejuruan dalam Menghadapi Masyarakat Ekonomi ASEAN (MEA). Journal. Ustjogja. Ac. Id, $1-6$.

Putri, M. P. (2016). Peran ( KPU ) Dalam Sosialisasi Pemilu Pada Pemilu Presiden 2014 di Kalimantan Timur ( Maslekah Pratama Putri ). Ejournal.Ilkom.Fisip-Unmul, 4(1), 30-43.

Sekolah, D. I., \& Kejuruan, M. (2013). Relevansi soft skill yang dibutuhkan dunia usaha/industri dengan yang dibelajarkan di sekolah menengah kejuruan. Universitas Stuttgart, 36(2), 107-118.

Suryani, E. (2005). Futari wa purikyua = Pretty Cure. 12. Kybernan (Jurnal Ilmu Pemerintahan), 1(2), 1-20. http://jurnal.unismabekasi.ac.id/index.php/kybernan/article/view/655 